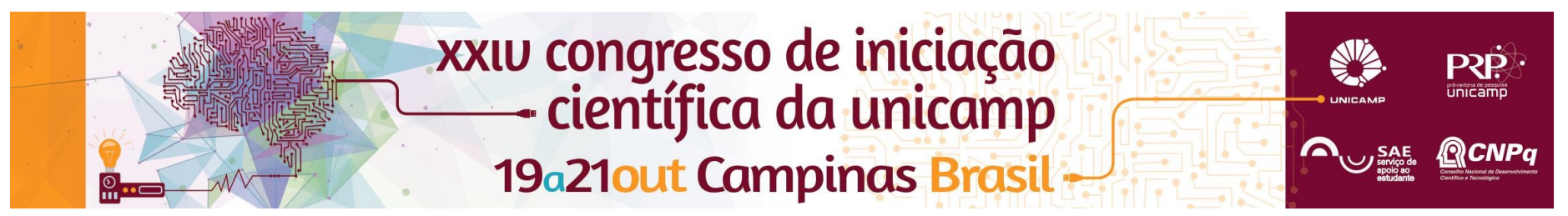

\title{
Relações entre o bem-estar psicológico, características sociodemográficas e qualidade de vida
}

\author{
Patricia lanhez Barreira, Wagner de Lara Machado.
}

\section{Resumo}

O presente estudo investiga a relação entre os componentes do bem-estar psicológico, variáveis sociodemográficas e a qualidade de vida relacionada à saúde, procurando entender como o desenvolvimento positivo e as características sociodemográficas afetam a percepção de saúde física. Para tanto foram utilizadas análises de regressão múltipla e a análise de rede, cuja técnica permite o tratamento multivariado de dados por meio da representação espacial/gráfica dos elementos e a relação entre eles.

\section{Palavras-chave:}

Bem-estar psicológico, qualidade de vida, análise de rede

\section{Introdução}

O bem-estar psicológico é um construto derivado de teorias sobre a clínica humanista-existencial, o desenvolvimento humano positivo e da saúde. Suas dimensões refletem o desenvolvimento positivo frente às tarefas evolutivas: autoaceitação, relações positivas com outros, autonomia, domínio sobre o ambiente, propósito na vida e crescimento pessoal (RYFF, 1989). A qualidade de vida é definida como "a percepção do indivíduo de sua posição na vida no contexto da cultura e sistema de valores nos quais ele vive e em relação aos seus objetivos, expectativas, padrões e preocupações" (WHOQOL Group, 1994, p.28), sendo um construto multidimensional que inter-relaciona o ambiente com aspectos sociais, psicológicos, físicos, crenças e relações sociais (FLECK, 2000). Nele se incluem variáveis como vitalidade, dor, saúde mental, saúde geral, aspectos emocionais, sociais e capacidade funcional. $O$ presente estudo tem como objetivo investigar a relação entre os componentes do bem-estar psicológico, variáveis sociodemográficas e a qualidade de vida relacionada à saúde, buscando elucidar as formas como o desenvolvimento positivo e as características sociodemográficas afetam a percepção de saúde física.

\section{Resultados e Discussão}

Figura 1. Rede de correlações parciais entre as variáreis investigadas

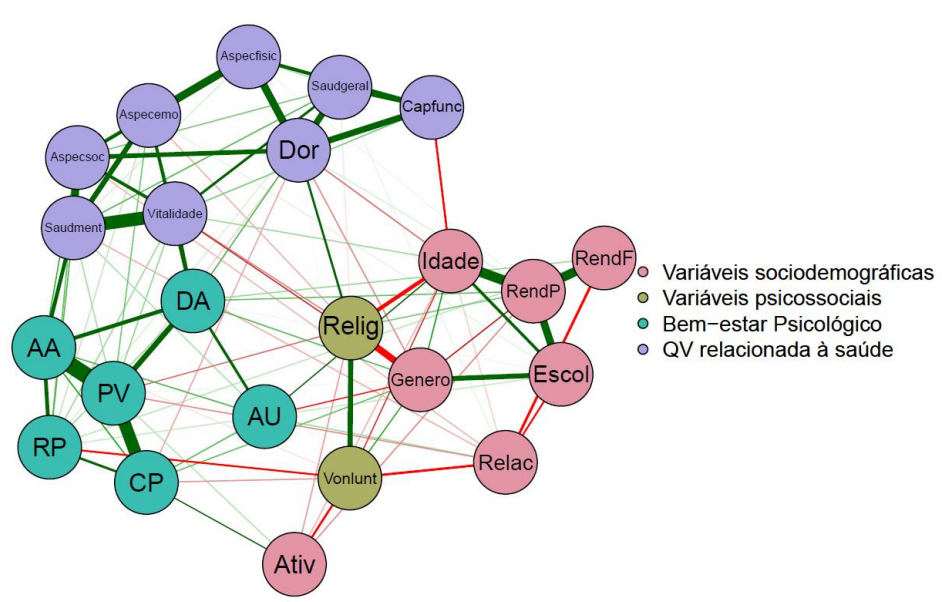

A análise do grafo obtido a partir do processamento das variáveis escolhidas explicitou que variáveis como dor, saúde mental, aspectos sociais (variáveis de qualidade de vida), propósito de vida, autoaceitação, domínio do ambiente (variáveis de bem-estar psicológico) e religiosidade tiveram um grande protagonismo nas relações com as demais variáveis. $\mathrm{O}$ domínio sobre o ambiente teve associações significativas com muitas outras variáveis, mostrando que manejar o ambiente para satisfazer necessidades é bastante importante para a manutenção da qualidade de vida e vice-e-versa. A autoaceitação obteve associações muito significativas e mais próximas dos fatores emocionais de qualidade de vida. A dor foi uma variável central entre outras de qualidade de vida, como capacidade funcional, aspectos emocionais, físicos e saúde geral, mantendo associações positivas com estas, mostrando o quando ela pode ser prejudicial à qualidade de vida da pessoa.

\section{Conclusões}

É possível concluir que, na interrelação entre qualidade de vida, bem-estar e aspectos sociodemográficos e psicossociais, o fato da pessoa ter um domínio sobre o ambiente em que vive, além de ter autonomia e autoaceitação, contribui muito para a percepção de uma melhor qualidade de vida. Além disso, a religiosidade estabeleceu muitas associações com as demais variáveis de bem-estar e qualidade de vida, mostrando ser importante principalmente para a percepção de dor.

\section{Agradecimentos}

À Pontifícia Universidade Católica de Campinas e ao Conselho Nacional de Desenvolvimento Científico e Tecnológico (CNPq) pelo financiamento.

FLECK, M.P.D.A. O instrumento de avaliação de qualidade de vida da organização Mundial da Saúde (WHOQOL-100): características e perspectivas The World Health Organization instrument to evaluate quality of life (WHOQOL-100): characteristics and perspectives. Ciência \& Saúde Coletiva, v. 5, n. 1, p. 33-38, 2000.

RYFF, C.D. Happiness is everything, or is it? Explorations on the meaning of psychological well-being. Journal of Personality and Social Psychology, v. 57, n. 6, p. 1069-1108, 1989.

WHOQOL Group. Development of the WHOQOL: Rationale and cur rent status. International Journal of Mental Health, v. 23, n. 3, p. 24-56, 1994. 